\title{
Behavior of Different Grafting Strategies Using Automated Technology for Splice Grafting Technique
}

\author{
José-Luis Pardo-Alonso ${ }^{1}$, Ángel Carreño-Ortega ${ }^{1, * \mathbb{B}}$, Carolina-Clara Martínez-Gaitán ${ }^{2}$ and \\ Hicham Fatnassi ${ }^{3}$ \\ 1 Department of Engineering, University of Almería, CIMEDES Research Centre, Agrifood Campus of \\ International Excellence (CeiA3), La Cañada de San Urbano, 04120 Almería, Spain; jolupa@ual.es \\ 2 Tecnova, Technological Centre: Foundation for Auxiliary Technologies in Agriculture, Almería Technology \\ Park, Avda. Innovation, 23, 04131 Almería, Spain; cmartinez@fundaciontecnova.com \\ 3 INRAE, University Nice Sophia Antipolis, CNRS, UMR 1355-7254 Institut Sophia Agrobiotech, \\ 06900 Sophia Antipolis, France; hicham.fatnassi@inrae.fr \\ * Correspondence: acarre@ual.es; Tel.: +34-950-214-098
}

Received: 16 March 2020; Accepted: 13 April 2020; Published: 16 April 2020

check for updates

\begin{abstract}
Even though the splicing graft technique is relatively recent, it has become the most commonly used grafting method for solanaceae, and in particular, for tomato. Today, almost everyone has standardized the use of plastic or silicone grafting clips, equipped with manipulating wings and a frontal opening, to ensure proper bonding and allow for wound healing. Numerous factors influence the success or failure of the grafting process, factors such as the seedling varieties combined, climatic conditions, pre-graft and post-graft care, cutting point, cutting angle, pressure of the clips, blade edge, or substrate water content, among others. In this work, several alternatives in the graft assembly and coupling protocol were evaluated. Having studied the different working alternatives for grafting using a robotic system, two modes of joining order were analyzed. It has been shown that there are $20 \%$ more recorded successes if one first joins the graft seedlings and then places the grafting clip to guarantee their union. In addition, we studied the different orientation alternatives for the cutting line and the seedling union with respect to the clip opening-there were approximately $10 \%$ more successes obtained in grafts where the splice-union cutting line between the two plants faced the clip opening.
\end{abstract}

Keywords: tomato grafting; splice-grafting technique; agricultural robot; automated grafting; agricultural machinery; grafting clips; tube grafting; slant-cut grafting; Japanese top grafting

\section{Introduction}

Horticultural seedling grafting is a relatively new technique, but its growth and importance are highly significant today [1]. It originated in Japan and Korea in the early 20th century, although it was not documented in a research journal until 1927 [2-5]. Its beginnings in horticulture in the late 1920s and early 1930s are associated with the cucurbitaceae family, where primitive grafting techniques were applied to watermelon, and later to cucumber. The first records collected for the solanaceae family were on eggplant grafts in the 1950s, while its use on tomato was not commercially introduced until the 1960s [3,6,7]. Very slowly but progressively, it was introduced in western countries in the early 1990s, yet it was not until the 21st century that interest in its use for large-scale horticultural crop became widespread $[8,9]$.

The uptake of grafting is motivated and encouraged mainly in response to policies that have opted to gradually eliminate chemical disinfectants from the soil as methyl bromide, which have very negative effects on the environment, and whose use is currently prohibited $[10,11]$. This prohibition 
comes in response to increasing social awareness, and also to a growing interest in developing organic and integrated agriculture. Although, today, the fight and resistance to soil pests and viral diseases remains the main objective for applying this technique [12], there are other reasons and particularities justifying its use. It is a faster and more effective tool for selecting desirable crop characteristics than natural screening, selection processes, or species hybridization $[13,14]$. Grafting increases the health and precocity of the plant, providing stronger and more vigorous root systems than in ungrafted plants, which leads to improved water and nutrient absorption [15-17]. Improved mineral nutrition can result in the significantly lower use of agrochemicals during cultivation [9], as well as better adaptability to environments where there is abiotic stress and potentially harmful and unfavorable conditions, such as water stress, thermal stress, and saline stress; there is also better performance in response to high heavy-metal concentrations $[5,12,14,18]$. In addition, grafted plants provide higher productivity, with fruit that is significantly larger than that from ungrafted plants [19] while other fruit characteristics, such as their shape, skin color, flesh texture and color, or concentration of soluble solids, are negatively influenced by the rootstock, despite being generally assumed as hereditary stem characteristics [15].

Grafting is a common practice in high value-added cucurbitaceous and solanaceous crops [20]. There are two basic grafting methodologies: One is where the grafting process retains the two root systems, that of the rootstock and of the scion (tongue approach grafting, side grafting); and the other is that in which a shoot from the scion is joined to the rootstock plant (cleft grafting, hole grafting, splice grafting) [21,22]. In the first case, less strict environmental conditions are required during the grafting period and the post-graft phase [23], but its application is complex in solanaceae, mainly because the plants are usually grafted very young when stem thickness is minimal (Figure 1).
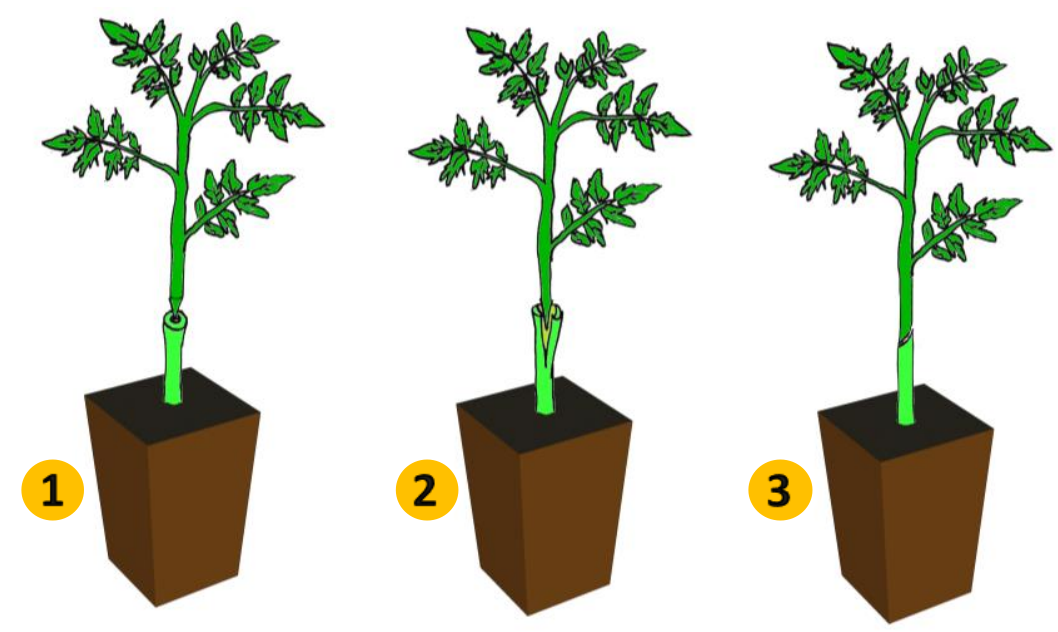

Figure 1. Common grafting methods to join scion and rootstock for solanaceae. Highlights the use of splice grafting technique. It is widely used as it is efficient and easy to execute. (1) Hole grafting, (2) cleft grafting, (3) splice grafting.

Splice grafting (also called slant-cut grafting, Japanese top grafting, or tube grafting) is currently the most common grafting method for tomato (solanum lycopersicum) worldwide [24]. The splice graft has a high success rate, is relatively simple to execute, and is even amenable to automation, so a large number of plants can be grafted in a short period of time [25]. Despite being a relatively recent technique, the splice grafting process has developed exponentially, especially when applied to solanaceae, and has been widely described and defined in much of the literature [25-29].

In the splice graft technique, the rootstock is cut (straight or beveled) below or above the cotyledons. A pronounced cutting angle creates more surface area than a flat cut, allowing more cells on the cut surfaces of the rootstock and scion to be in contact and, thus, fuse better. When cutting above the cotyledons, it is necessary to remove the rootstock regrowth throughout the life of the plant, whereas a 
graft below the cotyledons can facilitate the rooting of the scion because of its proximity to the ground, so that the grafted scion can bridge the rootstock, casting adventitious roots while completely removing the meristemal tissue from the rootstock [30]. The shoot is also bevel-cut with a complementary angle and a stem height that guarantee a similar diameter at the union. Both parts must be placed in close contact, holding together the union with a grafting clip or other passive device that ensures pressure between the cut surfaces of the rootstock and the shoot. One must make sure that the cambium area between the two seedlings is well aligned, ensuring good contact between the shoot and the rootstock's vascular system $[28,31]$. One advantage of the splicing method is that it allows grafting with smaller plants, which reduces pre-graft growing times and the space required in the growing chambers [22,32].

The first recorded splice graft tests were developed with graft tubes in the late 1950s, but these tubes were neither elastic nor had the side opening that they have today [33]. In the early 1990s, elastic tubes were developed and applied, very similar to those used nowadays, and, thus, achieved grafting times 2 to 3 times faster than the conventional method used up until then [34-36]. To ensure fusing between the plants, in the graft union, one can use a ceramic or bamboo pin fixed inside the stem, glue or adhesive plastic tape, and a clamp or an elastic clip in the form of a tube with or without a side slit $[9,37,38]$. In most countries today, there is standardized use of elastic tube-shaped clips with a longitudinal opening and side wings that facilitate handling and clip opening when positioning (Figure 2). Once the clips are in place, they tighten and fasten the seedlings securely during their healing phase.

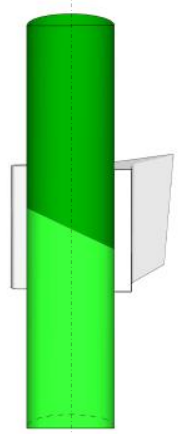

1

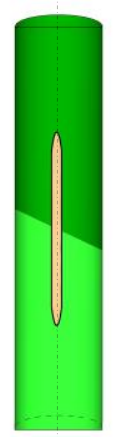

2

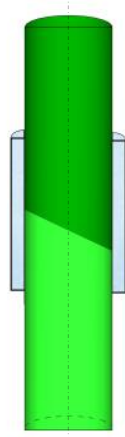

3

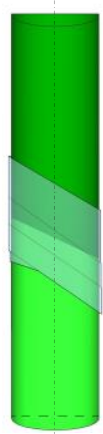

4

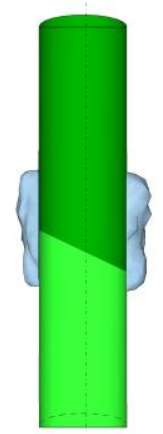

5

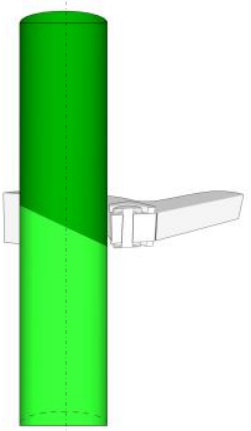

6

Figure 2. Common bonding and clamping systems used for solanaceae grafting. Highlights the use of clips. A section of the graft junction is showed, where the rootstock is light green and the variety is dark green. (1) Clip, (2) pin, (3) tube (with or without side opening), (4) adhesive plastic film, (5) glue, (6) gripper.

The use of graft pins has been common in south-east Asian countries but limited to those areas where the grafting clip use is not possible or they are not available, because of the added difficulty involved in the insertion operation. Using grippers is more common for thick stems such as cucurbitaceae; they are also significantly more expensive elements compared to tube-shaped clips. The grippers also need to be removed manually, whereas the tube clips will release by themselves as the plant grows (if they have a longitudinal opening); if they are closed tubes, they are manufactured using a material that expands as the stem thickness increases and degrades naturally over time [39]. Moreover, using tube-shaped elastic clips ensures a smoother grip and more distributed pressures, as well as minimizing water loss from the graft wounds [40]. The use of transparent film around such thin stems makes handling and placement difficult, especially when grafting is carried out manually. The use of instant glue has been adopted in some automated processes [41], or simply to support other grafting techniques to further secure the union [42].

The grafting techniques developed over the last century for vegetable cultivation have been varied and adapted to particular environments, media, and the technical skills available for their application [10]. Grafting techniques are, therefore, cultural techniques that still seem more an art than 
a science, born of the experience and dedication of farmers over centuries [43]. The manual grafting task has the problems of a low production ratio, high cost, and sometimes low quality. A robotics-based solution may be a good solution capable of meeting this challenge of vegetable grafting production, aiming to reduce these problems.

Regardless of the varieties chosen, and the treatments and pre-graft and post-graft conditions, different studies have been carried out that evaluate the influence of diverse factors when performing the splicing graft, which, in turn, influence the survival rate. Success depends on factors such as the cutting point (either above or below the cotyledons), the water content in the substrate at the time of cutting [44], the difference and ratio between the grafted seedling diameters, the cutting angle between the rootstock and the scion [45], the influence of the grafting clip pressure around the hypocotyl of the grafted plants, or the influence of cutting the shoots with a somewhat sharp blade [46].

This paper attempts to provide basic documented information on the splicing technique, analyzing the success rates and influence of different joining strategies used in the splicing graft technique. A robotic system is used that coordinates the work of two anthropomorphic robots; these manipulate and manage the displacement and positioning of the seedlings with external auxiliary passive electromechanical devices that condition, prepare, and perform the graft [47]. The placement order between the clip and the seedlings is analyzed, as well as the cutting angle orientation with respect to the side opening of the grafting clip, as the basis for its implementation in automated grafting equipment, or suitability for the hand-executed splice grafting technique using support equipment, or other fully automated equipment.

\section{Materials and Methods}

\subsection{Device Description}

To understand the influence of the different seedling grafting strategies on the success of the grafting process, an automated experiment was designed to harmonize the work processes and thereby avoid variation in the obtained results, as far as possible.

The rootstock and scion are cut to a precise angle of $60^{\circ}$; this ensures greater splicing graft success [45]. The cutting is performed using two simple devices, in which the seedling stems are placed in a slit that guarantees verticality. Once the seedlings are set in place, a pneumatic actuator advances a blade that makes the cut with a dry shock movement against the seedling, causing a clean stem bisection and ensuring cutting angle accuracy. The seedlings are placed into the grafting device by two Kuka industrial robotic arms (Agilus model R6 900 developed by KUKA Roboter GmbH). Each robot operates independently in handling each of the seedlings, one responsible for holding the rootstock and the other for the scion.

The grafting equipment on which the various splicing strategies were tested cuts each of the flexible plastic clips from a continuous reel, and then positions the grafting clip, thus ensuring the union between the rootstock and the scion (Figure 3). The process consists of two basic operations: (1) Preparation of the grafting clip by making a custom cut and (2) clamping the clip for optimal opening and placing it on the seedling to be grafted [47].

(1) In the first phase, the device makes a grafting clip from a continuous roll of plastic tube tape through the coordinated and sequential action of several pneumatic actuators and a blade cutting system. To do this, the first microcylinder (SMC CJPB10-5) clamps the continuous tube tape against a second cylinder (SMC CXSM15-15), which vertically pushes through the exact length required for the grafting clip. Finally, the tube is cut by a blade attached to the second cylinder (SMC CXSM15-15), with a clean dry shock cut.

(2) In the second phase, the grafting clip is clamped by a rotary actuator (Festo DM-6-90-P-A), which acts on a lever mechanism that presses the clip's side wings, thus opening the clip to its maximum. As a last step, once the clip is on, a cylinder (SMC CXSM25-70) horizontally scrolls the clip to align with the union point of the two graft seedlings. Once the graft is complete, the rotary 
actuator (which holds the clip open) releases the clip and removes itself from the union point, returning to its resting position.
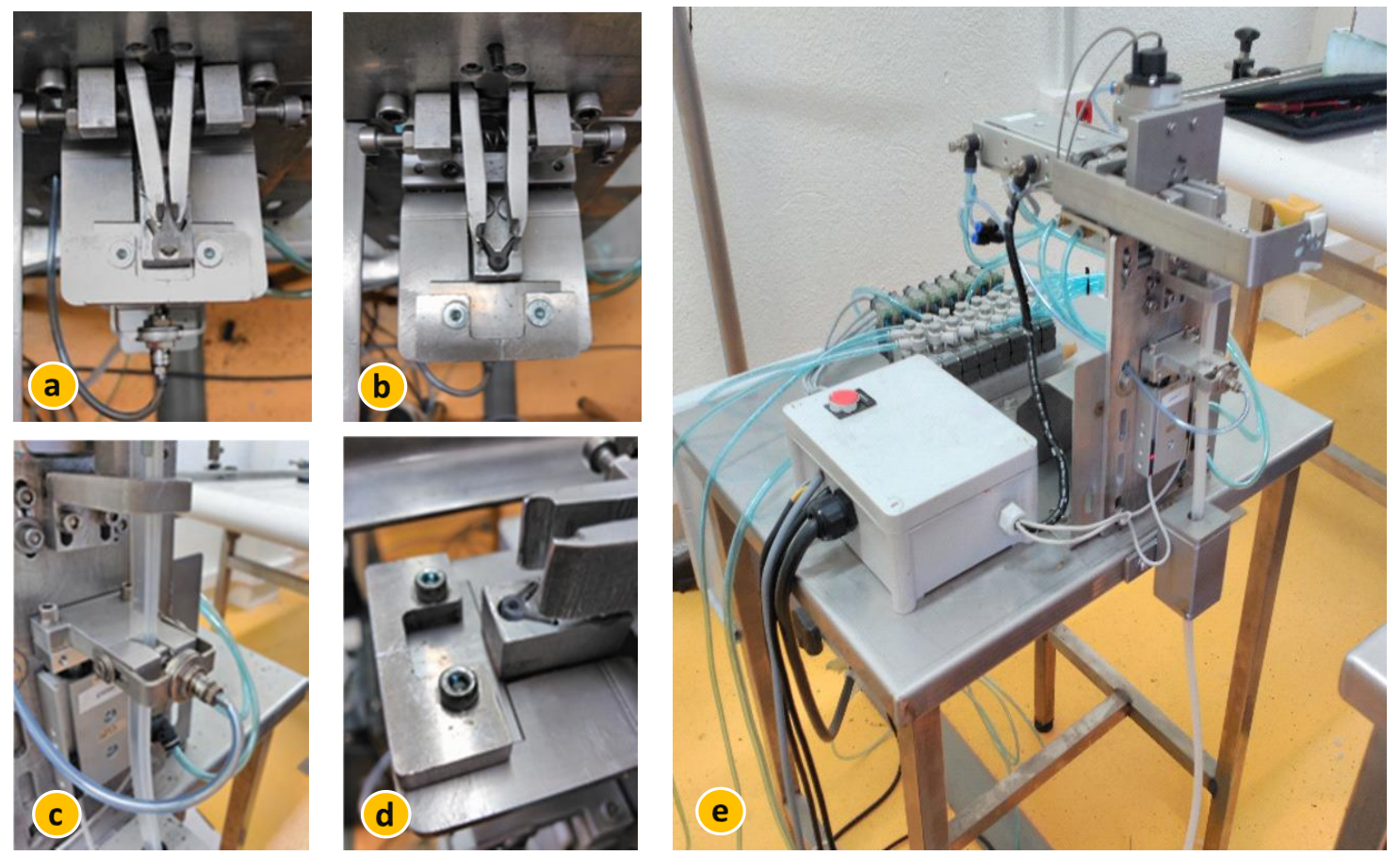

Figure 3. Detailed view of the device that dispenses and places the graft clip. (a) Pinching system with clip wings pressed, (b) clip clamping system (at rest), (C) and (d) elements used in the manufacture and clamping of grafting clips from continuous plastic tube, (e) overview of the equipment for making, dispensing, and securing the clips.

A passive fitting device is located at the meeting point of both seedlings and the grafting clip, which ensures correct seedling positioning. The seedling stems may suffer slight deviations or inclinations due their natural variability and search for a light source as they grow. The passive device is designed to correct these small deviations. It has two openings, one on top for the scion and one below for the rootstock, which guarantee the correct placement and housing of the seedlings. Both openings are connected by a channel, allowing sufficient space to fit both seedlings and the graft clip and to ensure that both seedlings are perfectly matched up.

Once the clip is positioned, the robot holding the scion graft releases and withdraws while the robot holding the rootstock graft stem likewise withdraws from the grafting point, so that the post-graft healing phase can begin.

The graft clips used in the test were taken from a continuous roll of flexible translucent plastic, equipped with a lateral opening; the $3.00 \mathrm{~mm}$ internal diameter is slightly oval to provide better grip and closure when the rootstock and scion stem diameters are not the same, and it is also equipped with side wings for opening and placement. These types of clips, widely used in splice grafting, can be purchased on continuous reels for automation purposes. They can be cut to different lengths, are easy to handle and adapt as the callus heals and the stems thicken, and they eventually fall off by themselves.

\subsection{Definition of the Operating Conditions}

The research was performed at the Tecnova Technology Centre: Foundation for Auxiliary Technologies in Agriculture, Almería ( $\left.36^{\circ} 52^{\prime} 38^{\prime \prime} \mathrm{N}, 2^{\circ} 19^{\prime} 59^{\prime \prime} \mathrm{W}\right)$ between March and June 2017. The rootstock used in the experiment was the interspecific hybrid 'Maxifort' (De Ruiter Seed ${ }^{\mathrm{TM}}$, Spain), 
while the scion used was 'Ventero' (De Ruiter Seed ${ }^{\mathrm{TM}}$, Spain). Both seed types are commonly used in seedlings destined for manual grafting using the 'tomato on tomato' (T/T) splicing technique, so their pre-experiment compatibility to the automated grafting system has already been demonstrated.

Prior to the grafting process, the plants were cultivated in the seedbed and nursed until the rootstock and scion achieved a similar growth state; for this to occur, the scion was planted 2 to 5 days before the rootstock so that both seedlings had similar stem diameters. The seedlings were grafted when they had 2 to 4 well-defined true leaves. We tried to pair rootstock and scion stems of similar diameters. The grafting operation should be carried out over a very short period of time. During this process, the environmental conditions in the work environment were regulated with temperatures between $20^{\circ}$ and $25^{\circ}$, and relative humidity conditions of between $75 \%$ and $95 \%$, with stable lighting conditions of non-direct daylight. Splice grafting requires stringent environmental conditions during the healing process, with high relative humidity (HR) and an optimal temperature in order to reduce stem transpiration until the rootstock and the vascular tissue of the stem are healed and water and nutrient transport is restored [48]. After each of the grafting trays was completed, they were immediately placed in a small healing chamber; this comprised a tunnel slightly larger than the size of each tray, covered by a transparent film. This tunnel was placed in a chamber where climate conditions were controlled throughout the healing process. During the first $48 \mathrm{~h}$, the plants were unlit to reduce transpiration and evaporation. Over the following days, the light intensity was increased, establishing a $14 \mathrm{~h}$ photoperiod with a value of $100 \mu \mathrm{mol}-\mathrm{m}^{-2} \mathrm{~s}^{-1}$ of Photosynthetically Active Radiation (PAR), (x3000 Lux) non-direct and diffuse light, as recommended for the callus formation stage $[6,49]$. This illumination was gradually increased over successive days while the temperature was controlled between 23 and $30^{\circ} \mathrm{C}$ (an average of $26^{\circ} \mathrm{C}$ ), using a variable setting point in the healing chamber, slightly varying the daytime and night-time conditions. Relative humidity (HR) was initially established between $95 \%$ and $75 \%$ in the first phase. It was then gradually reduced over subsequent days for outdoor acclimatization.

For the first three days, the grafts were not handled. After the fourth day, the grafts underwent a thorough visual inspection on a daily basis, evaluating the changes and the healing process in each of them, assessing the natural evolution of the grafts and analyzing other symptoms and external signs that might determine their success or failure. This follow-up was performed for 14 days after grafting. Non-destructive techniques were used for the evaluation of graft success, based on direct observation of the evolution of the grafting junction. Visual inspection of evidences was evaluated such as vigor or sagging on leaves and stems, consummation of the callus, appearance of necrotic areas, substantial differences between scion and rootstock part growth, or the progressive appearance of new axillary buds in the scion.

\subsection{Experiments}

The graft takes place when both the plants are placed in intimate contact with each other, held in position by the grafting clip. To carry out the experiment, 6 grafting strategies or treatments were analyzed. Two alternatives were established regarding the grafting order (Figure 4):

1. One consisted of first placing the grafting clip at the attachment point, and then inserting the rootstock and the scion, with both seedlings being inserted at the same time but from different orientations (Clip and Stems, CS).

2. The other consisted of first placing the seedlings into the passive fitting device and then approximating and positioning the grafting clip onto their attachment point (Stems and Clip, SC). 

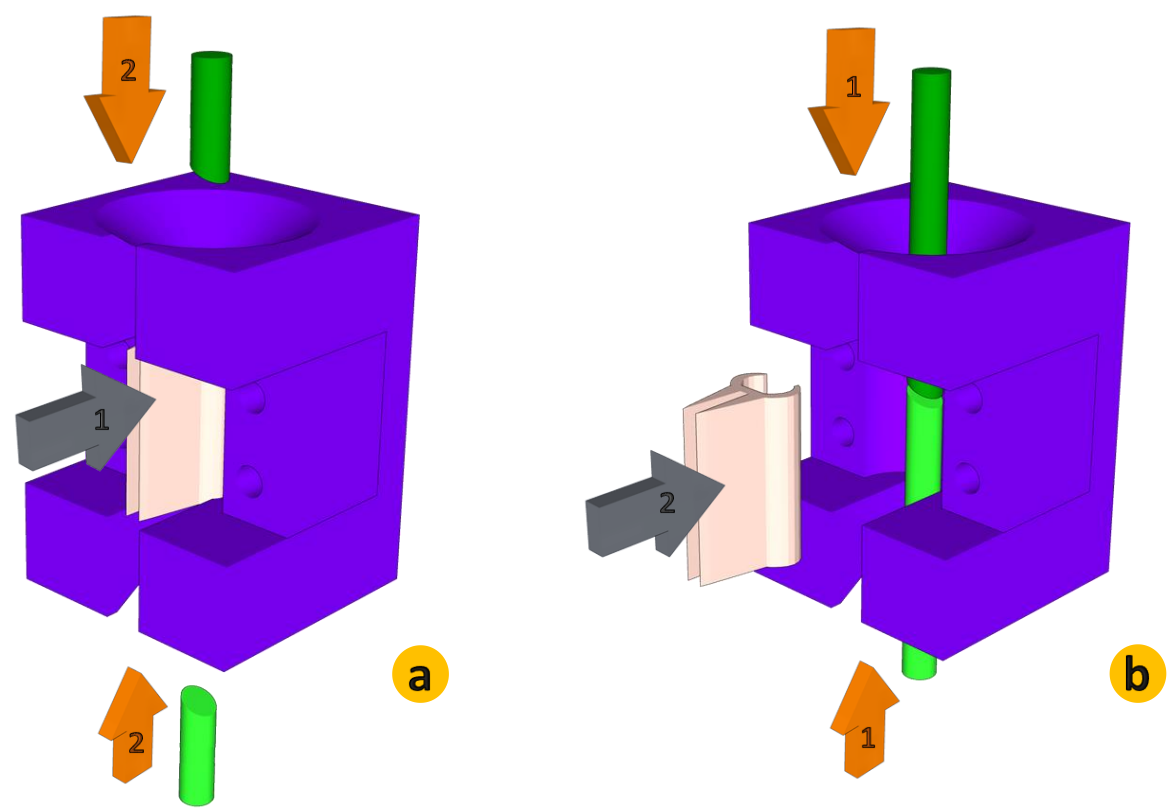

Figure 4. Passive fitting device, with seedlings (rootstock and scion) and the grafting clip at the graft union point. This piece allows the assembly operation, where the two robots and the clip dispensing device consummate the graft. (a) First placement of the grafting clip, and then splice of the seedlings (CS). (b) First splice of the seedlings, and then placement of the grafting clip (SC).

For each of the grafting-order alternatives, three combinations of the seedling surface orientation were tested with respect to the grafting clip opening (Figure 5):

(1) In the first test option, the stems were attached so that the union line was facing the side opening (side, S).

(2) In the second test option, the stem union was carried out in such a way that the rootstock was to the front, hiding the union surface behind it (front rootstock, FR).

(3) In the third test option, the stem union was carried out with the scion graft facing forward, thus hiding the union surface behind the scion (front scion, FS).
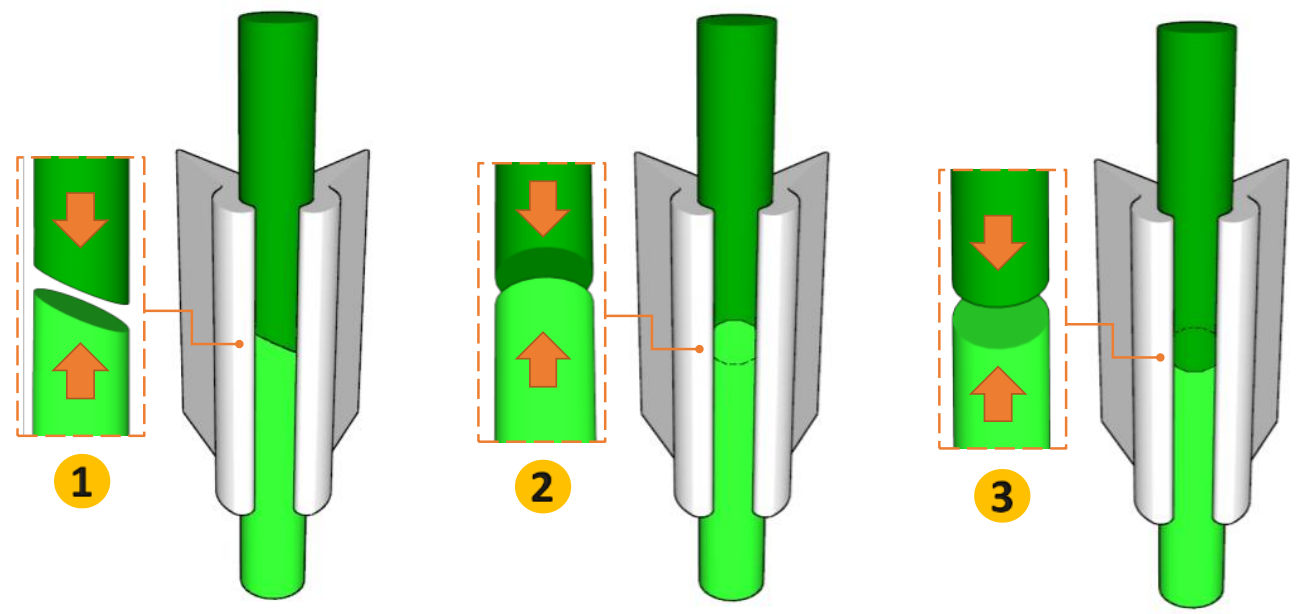

Figure 5. Outline of the orientation combinations between grafted seedlings regarding the grafting clip. (1) Profile union surface (S). (2) Union surface with the rootstock forward (FR). (3) Union surface with the scion forward (FS).

By combining these variables, we analyzed a total of 6 different grafting alternatives in terms of their success and the influence they had on the grafting process. A total of 900 grafting trials were 
performed, divided into 6 replicates, with 25 trials for each of the treatments under study per replicate. The sum of the experimental blocks, each of equal size, comprised a total of 150 grafts for each of the 6 alternatives tested, with the aim of determining their influence on grafting success (Figure 6). Each replicate, carried out on a particular date, was treated to identical cultivation preconditions, handling, and post-graft healing. Furthermore, for each of the replicates, the positional order on the tray for each grafting strategy tested was altered, thereby neutralizing the dependence on that factor.

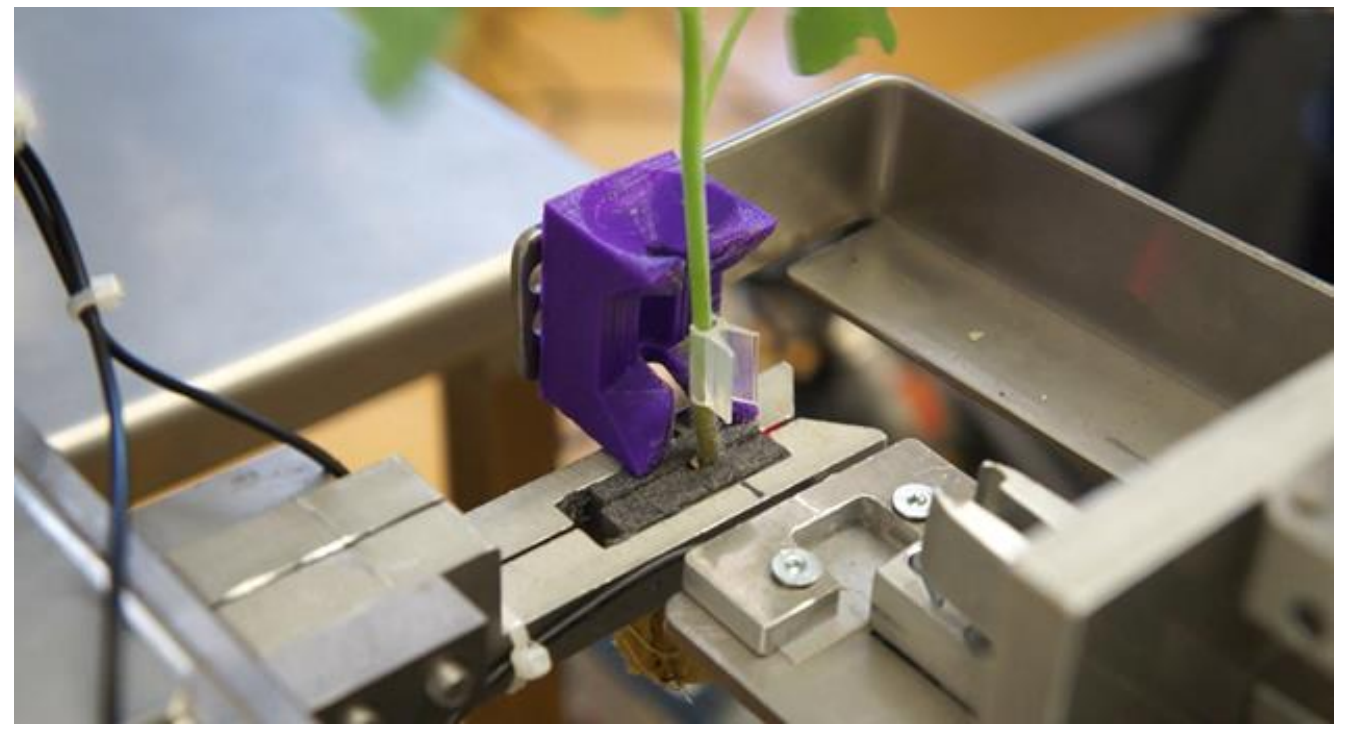

Figure 6. Detailed view of the fitting device and the grafting clip placement. It can be seen that the grafted plant is clamped by the robot that holds the rootstock and that the grafting clip is in place. Demonstrative video of the system: https://youtu.be/CgJE3NxJ0sA (accessed on 1 April 2020).

Statistical analysis of the collected data was performed using MiniTab v.18.1 software. The results underwent variance analysis with confidence levels of $95 \%$, and contrast tests were applied using Tukey's test (the honestly significant difference (HSD) test). Tests that failed for reasons other than the technique used were eliminated from the process.

\section{Results and Discussion}

The methods described have evaluated six different work alternatives. The data analysis process in the present study included two stages: On the one hand, the evaluation of the trials has involved an analysis of the success of the grafts with different strategies, and on the other, the study of the possible causes that cause said failure. Seedlings were manually selected and matched by stem thickness to avoid dependence on the results with this factor. The seedlings were cut mechanically, and they were located to be gripped by the robots for their guidance of the displacements to the point of completion of the graft. Analyzing the experimental results, it can be seen that both factors, the order of assembly and orientation of the stems within the clip, affect the success of the graft (Figure 7).

The study alternatives allow us to group and study the results of, on the one hand, the order in the linking strategy, and on the other hand, the orientation of the plants inside the clip. Having performed the hypothesis test, we can estimate that there are statistically significant differences between the grafting strategies used to perform the splice grafting depending on the order in which the process is undertaken (Table 1). 


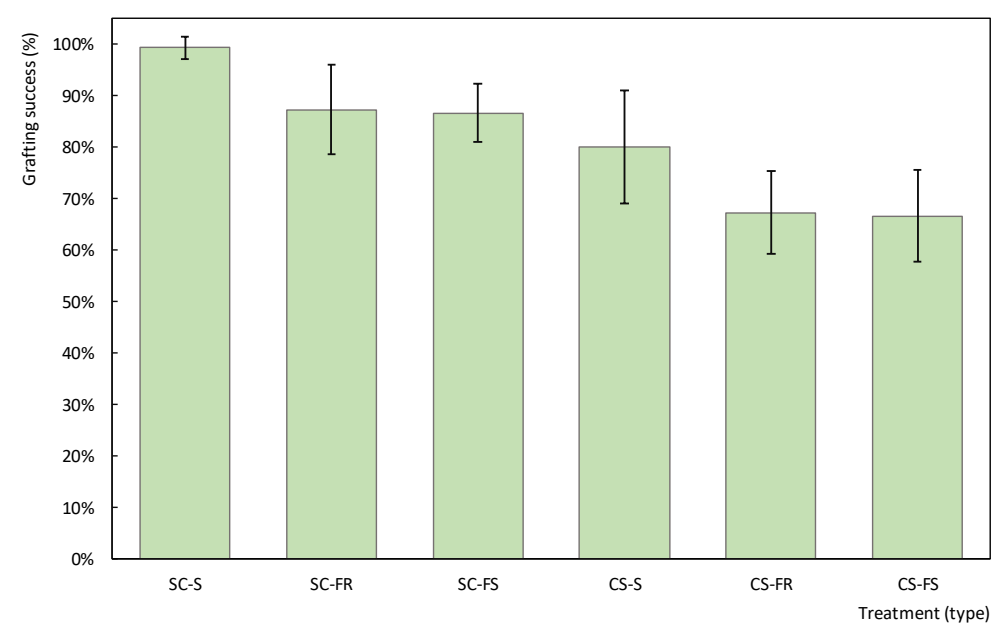

Figure 7. Grafting success for different test techniques. Success rate includes standard deviation, calculated from 6 replications.

Table 1. Comparison between success averages tested for different placement orders. Grouping of the comparisons applying Tukey's honestly significant difference (HSD) test. Significance level $p<0.05$.

\begin{tabular}{cccccccc}
\hline Placement Order & N & Grafts & Mean (Success) & Variance & St. Error & 95\% CI & $\begin{array}{c}\text { Grouping } \\
\text { (Tukey's HDS) }\end{array}$ \\
\hline Seedlings-Clips (SC) & 18 & 450 & $91.11 \%$ & 0.00083 & 0.0733 & $(0.8717 ; 0.9505)$ & $\mathrm{a}$ \\
Clip-Seedlings (CS) & 18 & 450 & $71.33 \%$ & 0.02542 & 0.0902 & $(0.6740 ; 0.7527)$ & $\mathrm{b}$ \\
\hline
\end{tabular}

Approximating the seedlings until their free surfaces are in contact and then fitting the grafting clip guarantees greater success in the splice-grafting process (SC). This difference in success, around $20 \%$ higher, is possibly due to less mistreatment of the seedlings when these are inserted into the clip through their lateral opening, instead of being introduced through their upper and lower holes. Failures were classified and grouped into five categories, according to the origin that gave rise to the failed graft (Figure 8). From analyzing the failures recorded at the time of the grafting, we can see that, for the most part, for the strategy of junction order SC, most failures were due to pinches caused on the stems by the clip, despite being approximate with maximum opening. The total failure rate did not reach $10 \%$ for SC. However, for the strategy of junction order CS, these were due to frictional chafing and wounds occurring when the stems were inserted into the clip holes, or because of deformation or damage on the joined surfaces with the stem twisting on itself as it was inserted as a guide inside the clip. The total failure rate was close to $30 \%$ for CS.

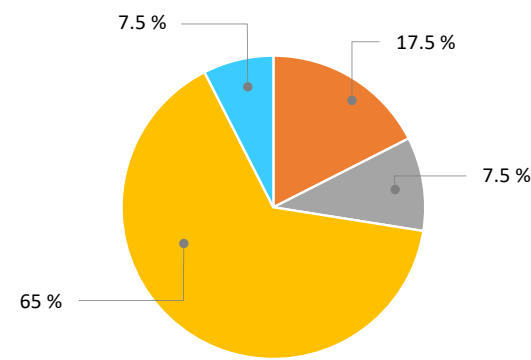

SC

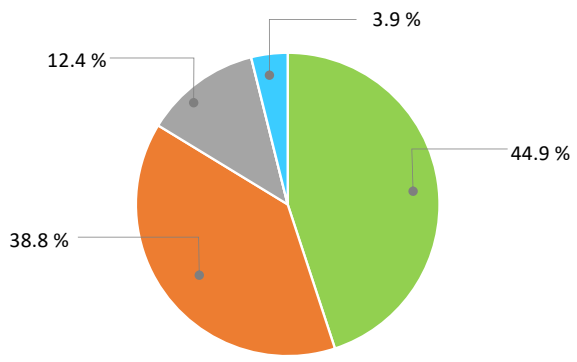

CS

$$
\square \text { Fail type 1 } \square \text { Fail type 2 } \square \text { Fail type 3 } \square \text { Fail type 4 } \square \text { Fail type 5 }
$$

Figure 8. Distribution of unsuccessful grafts according to different causes, depending on the order in which the process is undertaken. Fail type 1: Stem tip bent over on itself. Fail type 2: Scratches in guiding and positioning. Fail type 3: Separation between stems (not well-joined). Fail type 4: Pinching off the clip. Fail type 5: Other non-appreciable failures in the grafting process. 
Similarly, we can conclude that there are statistically significant differences between the orientation combinations of the joint surfaces between the seedlings with respect to the grafting clip opening (Table 2).

Table 2. Comparison between the average successes of the different orientations tested. Grouping of comparisons applying Tukey's HSD test (honestly significant difference). Significance level $p<0.05$.

\begin{tabular}{cccccccc}
\hline Orientation & N & Grafts & Mean (Success) & Variance & St. Error & $\mathbf{9 5 \%}$ CI & $\begin{array}{c}\text { Grouping } \\
\text { (Tukey's HDS) }\end{array}$ \\
\hline Side (S) & 12 & 300 & $89.67 \%$ & 0.00135 & 0.1150 & $(0.8278 ; 0.9655)$ & $\mathrm{a}$ \\
Front R (FR) & 12 & 300 & $77.33 \%$ & 0.00267 & 0.1198 & $(0.7045 ; 0.8422)$ & $\mathrm{b}$ \\
Front S (FS) & 12 & 300 & $76.67 \%$ & 0.00075 & 0.1167 & $(0.6978 ; 0.8355)$ & $\mathrm{b}$ \\
\hline
\end{tabular}

Orientating the seedlings by placing the union surface in front of the vertical clip opening (S) resulted in a greater success rate than orientating the graft by positioning the union surface with either the rootstock or scion in front of the clip opening. This difference in success, around $10 \%$ higher, is possibly due to the conventional clips used being prepared to make a clamping force in that determined orientation, compared to the other orientation alternatives. Sometimes, the failures reported were mainly due to the direction of tightening exerted by the clip sides, where the proper directional pressure was not applied, to keep the graft surfaces in intimate contact, or there was not a sufficient level of pressure. Moreover, because of the lack of protection in the clip opening area, the pointed end is free and sometimes loses contact with the other seedling surface. In a similar way, failures were classified and grouped into five categories, according to the origin that gave rise to the failed graft (Figure 9). For the strategy of junction orientation S, most failures were due to the stem tip bent over on itself or scratches and chafing in guiding and positioning the stem into the clip. The total failure rate was slightly higher than $10 \%$ for S. For junction orientation FR and FS, these failures are still the most important, but there is an increase in failures due to pinching off the stems by the clip, as these are slightly separated before tightening, and the lateral opening of the graft clip is limited. The total failure rate was higher than $25 \%$ for FR and FS alternatives.
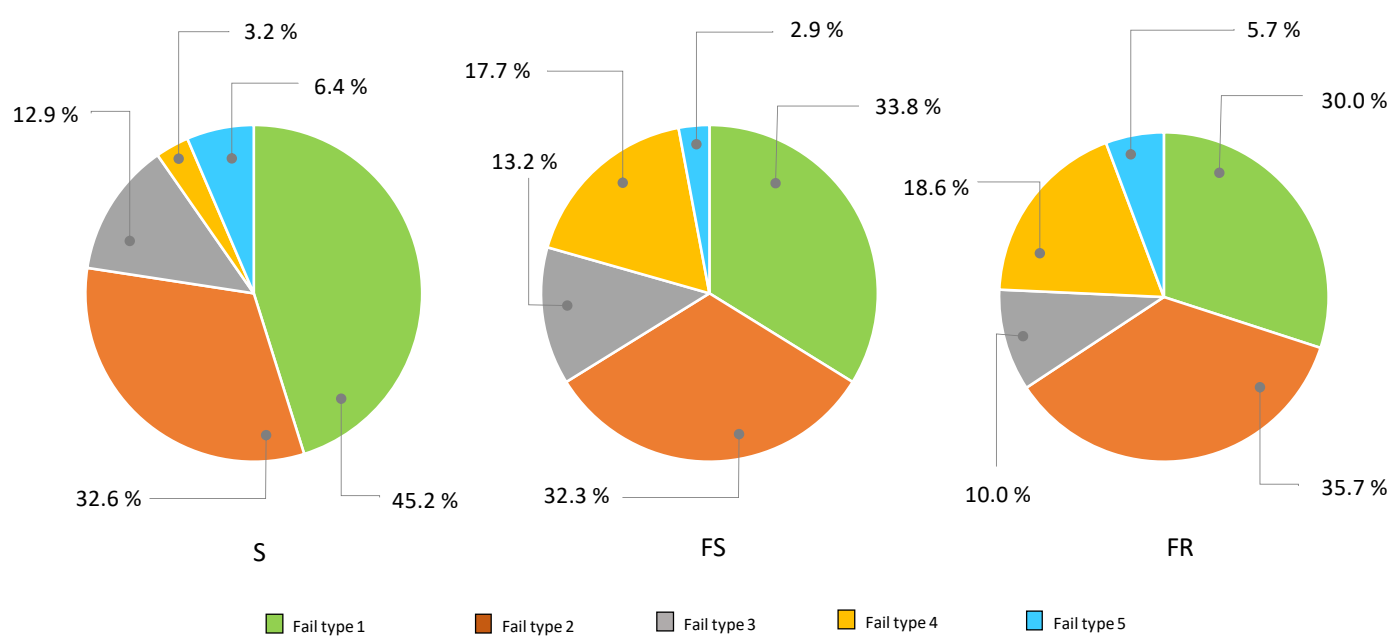

FS

FR

Figure 9. Distribution of unsuccessful grafts according to different cause, depending on the orientation in which the process is undertaken. Fail type 1: Stem tip bent over on itself. Fail type 2: Scratches in guiding and positioning. Fail type 3: Separation between stems (not well-joined). Fail type 4: Pinching off the clip. Fail type 5: Other non-appreciable failures in the grafting process.

Consequently, the best grafting strategy tested to carry out the splicing graft was order-dependent; that is to say, positioning the seedlings first, and then fitting the grafting clip. It also depends on the seedling orientation, placing the union line perpendicular to the clip opening (Figure 10). 


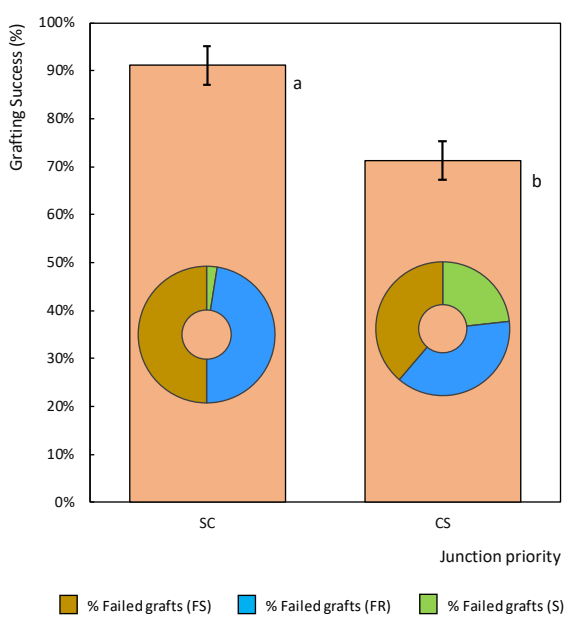

(a)

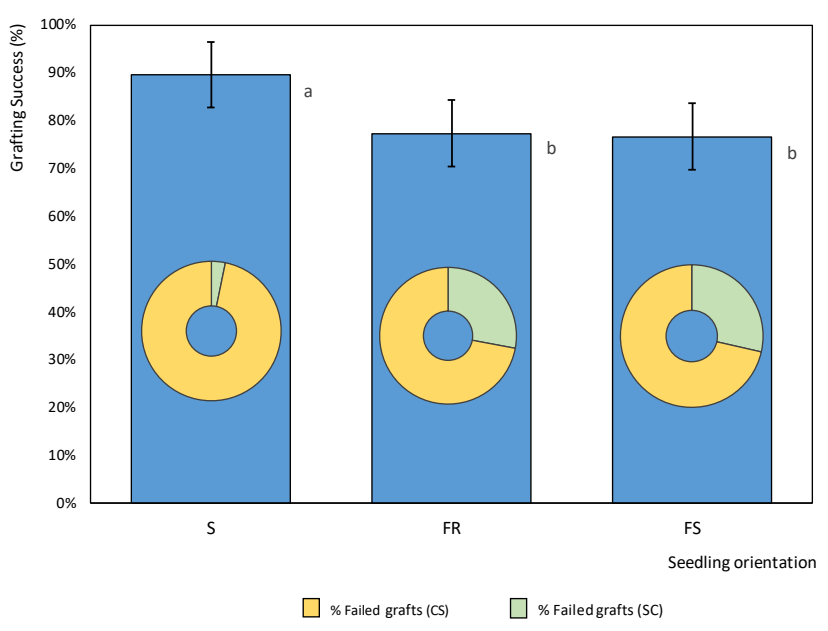

(b)

Figure 10. Grouping of information using Tukey's method with 95\% confidence. The success rate includes the typical error. (a) Comparison of success for different orders in the graft assembly process. Inside, the ring graphs show the \% of failures for each orientation in the junction. (b) Comparison between different orientations in the union. Grouping the information using Tukey's method with $95 \%$ confidence. The success rate includes integrated circuits. Inside, the ring graphs shows the \% of failures for each order in the junction.

It is evident that manual grafting has several problems: (1) Skilled workers are required, which increases the cost of grafted plants [50]; (2) large volumes of labor are required in short periods of time, requiring a large production scale; (3) frequently, grafted plants present a low quality of the union as a result of the manual and repetitive process, under extreme conditions of the working environment (high temperature and humidity), in order to fulfil the objective of an intensive production. Further, when hand grafting is performed in nurseries by specialized personnel, it is common to first insert the cut rootstock stem along the grafting clip halfway, orienting the opening of the grafting clip along the side of the graft cut. Then, the scion is introduced into the middle of the still-open tube at the appropriate orientation and to the necessary depth so that the cut surfaces of both seedlings come into contact [28]. This order in the work method is a consequence of the limitations arising from working with two hands, forcing the graft handler to clasp with one hand and operate with the other.

These problems make it difficult to meet the increasing production requirements and have favored the search for solutions based on automatic grafting machines, whose developments try to fill a growing potential market $[3,9,51]$. The results of this study aim to highlight the importance of applying an optimal automated work strategy for tomato grafting using the splice grafting technique and using conventional grafting clips.

The success rate for manual graft production, for workers with a certain degree of skill and experience, is around 150-240 grafts/h (with success rates between $81 \%$ and $91 \%$ ) $[47,52,53]$. In contrast, if we carry out the automated grafting described in the present trial, applying the most successful resulting strategy, consisting of an assembly order comprising a profile union surface of stems (S), and over these to couple the graft clip (SC), which presents $99 \%$ success results in the assembly phase to which the other processes that complete the grafting task must be subtracted. These results refer exclusively to evaluating the mechanical operation of the assembly, and can be applied to other varieties of solanaceae, as long as the same criteria of the size of seedlings are used, as well as the same strategy of working.

The system used to develop the method described in this article is based on using two industrial robots for plants handling and an external system responsible for positioning the grafting clip, all held by a passive support that allows the three elements: The rootstock seedling, the scion seedling, and the grafting clip to be positioned. There are, therefore, three manipulative elements acting 
together and in a coordinated fashion. Such a system cannot be directly extrapolated to grafting carried out exclusively by hand, as the graft handler, however experienced, only has two hands to manipulate and execute the process. However, it can be applied to fully automated systems and even semi-automated systems (based on manual handling by the operator supported by external clip fitting devices). These experimental results were directly extrapolated successfully for application to the complete automated splice grafting process using conventional industrial robotics [47].

\section{Conclusions}

To summarize, we can say that when performing robotic grafting, the operation is $20 \%$ more successful if the grafting plants are joined first, and the grafting clips are then fitted to guarantee their bonding rather than prepositioning the grafting clip and then inserting both plants. Furthermore, when considering the different alternatives for orientating the cutting line of the seedling union with the grafting clip opening, we observe a 10\% higher grafting success rate when the bevel cutting line is orientated perpendicular to the clip opening compared to when the rootstock or scion is orientated toward the clip opening. These results for the alternative joining and orientation methods prove to be the same in combination as they are when considered separately, that is to say, that the most successful strategy for performing the graft is to first position the plants and then insert the grafted seedlings into the clip with the cut line perpendicular to the clip opening.

Author Contributions: J.-L.P.-A. conceived and designed the experiments, performed the experiments, collected and analyzed the data, interpreted the results and developed the manuscript. Á.C.-O. conceived and designed the experiments, analyzed the data, interpreted the results, and developed the manuscript. C.-C.M.-G. conceived, designed and performed the experiments. H.F. provided constructive suggestions regarding the experiment analysis. All authors have read and agreed to the published version of the manuscript.

Funding: This research received no external funding.

Acknowledgments: This study was supported by Tecnova, Technological Centre: Foundation for Auxiliary Technologies for Agriculture. The authors would like to thank all the employees involved for their contributions to the experimental setting and data collection.

Conflicts of Interest: The authors declare no conflict of interest.

\section{References}

1. Velasco-alvarado, M.D.J.; Castro-brindis, R.; Avitia-garcía, E.; Castillo-gonzáles, A.M.; Sahagún, J. Proceso de Unión del Injerto de Empalme en Jitomate (Solanumly copersicum L.). RevistaMexicana deCienciasAgrícolas. 2017. Available online: http://www.redalyc.org/html/2631/263152411004/ (accessed on 19 February 2020).

2. Tateishi, K. Grafting Watermelon onto Pumpkin. J. Jpn. Hortic. 1927, 39, 5-8. Available online: http://cals.arizona.edu/grafting/sites/cals.arizona.edu.grafting/files/TranslationofTateishi1927.pdf (accessed on 29 February 2020).

3. Lee, J.-M.; Oda, M. Grafting of Herbaceous Vegetable and Ornamental Crops. Hortic. Rev. 2003, 28. [CrossRef]

4. Kubota, C. History of Vegetable Grafting. 2016, pp. 1-5. Available online: http://www.vegetablegrafting.org/ wp/wp-content/uploads/2018/04/History-VegetableGrafting3-1-18.pdf (accessed on 29 February 2020).

5. Maurya, D.; Pandey, A.K.; Kumar, V.; Dubey, S.; Prakash, V. Grafting techniques in vegetable crops: A review. Int. J. Chem. Stud. 2019, 7, 1664-1672.

6. Kubota, C.; McClure, M.A.; Kokalis-Burelle, N.; Bausher, M.G.; Rosskopf, E.N. Vegetable grafting: History, use, and current technology status in North America. Hortscience 2008, 43, 1664-1669. [CrossRef]

7. Alvarez, C.; Herzog, D. La técnica del Injerto (Presentation by Rijk Zwaan Ibérica). Rijk Zwaan Ibérica. 2011. Available online: https://es.slideshare.net/directorarica/presentacin-injerto-semilleros (accessed on 19 February 2020).

8. Bernal Alzate, J.; Rueda Puente, E.O.; Grimaldo Juárez, O.; González Mendoza, D.; Cervantes Díaz, L.; García López, A. Studies of Grafts in vegetables, an alternative for agricultural production under stress conditions: Physiological responses. J. Plant Sci. Phytopathol. 2018, 6-14. [CrossRef]

9. Lee, J.-M.; Kubota, C.; Tsao, S.J.; Bie, Z.; Echevarria, P.H.; Morra, L.; Oda, M. Current status of vegetable grafting: Diffusion, grafting techniques, automation. Sci. Hortic. 2010, 127, 93-105. [CrossRef] 
10. Fallik, E.; Ilic, Z. Grafted vegetables-The influence of rootstock and scion on postharvest quality. Folia Hortic. 2014, 2, 79-90. [CrossRef]

11. Pérez-Alfocea, F. Why should we investigate vegetable grafting? Acta Hortic. 2015, 1086, 21-29. [CrossRef]

12. Chen, Y.C.; Chang, W.C.; Wang, S.T.; Lin, S.I. Development of a grafting method and healing conditions to improve cabbage head quality. HortTechnology 2019, 29, 57-64. [CrossRef]

13. Rouphael, Y.; Schwarz, D.; Krumbein, A.; Colla, G. Impact of grafting on product quality of fruit vegetables. Sci. Hortic. 2010, 127, 172-179. [CrossRef]

14. Chiu, Y.C.; Chen, S.J.; Wu, G.; Lin, Y. 3D Computer-aided human factor engineering analysis of a grafting robot. J. Agric. Saf. Health 2006. Available online: https://pdfs.semanticscholar.org/4e1a/ 9520e51e475fb067112841643d23689994a4.pdf (accessed on 19 February 2020).

15. Lee, J.-M. Cultivation of grafted vegetables 1. Current status, grafting methods, and benefits. HortScience 1994, 29, 235-239. [CrossRef]

16. Ashraf, M.A.; Kondo, N.; Shiigi, T. Use of Machine Vision to Sort Tomato Seedlings for Grafting Robot. Eng. Agric. Environ. Food 2011, 4, 119-125. [CrossRef]

17. Enzo, M. Tomato Grafting. Young Plant Business Trends. Syngenta Solutions in Production Technology. 2015. Available online: https://www.syngenta.it/file/2141/download?token=7r50dcUd (accessed on 19 February 2020).

18. Colla, G.; Rouphael, Y.; Cardarelli, M.; Salerno, A.; Rea, E. The effectiveness of grafting to improve alkalinity tolerance in watermelon. Environ. Exp. Bot. 2010, 68, 283-291. [CrossRef]

19. Belmonte-uren, L.J.; Garrido-cardenas, J.A.; Camacho-ferre, F. Analysis of World Research on Grafting in Horticultural Plants. HortScience 2020, 55, 112-120. [CrossRef]

20. Djidonou, D.; Gao, Z.; Zhao, X. Economic analysis of grafted tomato production in sandy soils in northern Florida. Horttechnology 2013, 23, 613-621. [CrossRef]

21. De Miguel, A. II Jornadas Soobre Semillas y Semilleros Hortícolas. 1995. Available online: http://www.juntadeandalucia.es/export/drupaljda/1337170141II_Jornadas_sobre_Semillas_y_Semilleros_ Horticolas_BAJA.pdf (accessed on 19 February 2020).

22. Draie, R. Influence of grafting method in the quality of tomato seedlings grafted and intended for commercialization. IJSEAS 2017, 3, 2395-3470.

23. Garrido, J.C.G. Técnicas de Cultivo y Comercialización de la Sandía. 2015. Available online: https://www. publicacionescajamar.es/series-tematicas/agricultura/tecnicas-de-cultivo-y-comercializacion-de-la-sandia (accessed on 19 February 2020).

24. Singh, H.; Kumar, P.; Chaudhari, S.; Edelstein, M. Tomato Grafting: A Global Perspective. HortScience 2017, 52, 1328-1336. [CrossRef]

25. Johnson, S.; Kreider, P.; Miles, C. Vegetable Grafting: Eggplants and Tomatoes. 2013. Available online: http://pubs.cahnrs.wsu.edu/publications/wp-content/uploads/sites/2/publications/fs052e.pdf (accessed on 19 February 2020).

26. De Miguel Gómez, A. Serie Documentos: El Injerto de Plantas de Tomate. 2011. Available online: www.poscosecha.com/es/publicaciones/ (accessed on 19 February 2020).

27. Hartmann, H.T.; Kester, D.E.; Davies, F.T.; Geneve, R.L. Principles of grafting and budding. In Plant Propagation. Principles and Practices, 8th ed.; Pearson: London, UK, 2010; Chapter 11; ISBN 978-0-13-501449-3.

28. Guan, W.; Hallett, S. Vegetable Grafting. Techniques for Tomato Grafting. Horticulture and Landscape Architecture, (HO-260-W). 2016, pp. 1-8. Available online: https:/extension.purdue.edu/extmedia/HO/HO260-W.pdf (accessed on 19 February 2020).

29. Oda, M. Grafting of Vegetables to Improve Greenhouse Production; Food and Fertilizer Technology Center: Taipei, Taiwan, 1999; 11p.

30. Bausher, M.G. Road, South Rock, Pierce, Fort Graft Angle and Its Relationship to Tomato Plant Survival. Hort Sci. 2013, 48, 34-36. Available online: http://hortsci.ashspublications.org/content/48/1/34.short (accessed on 19 February 2020). [CrossRef]

31. Erin, R.; Cristina, P.; Francesco, D.G. Crop Specific Grafting Methods, Rootstocks and Scheduling: Tomato. USDA-ARS, Fort Pierce, Florida. 2017, pp. 1-13. Available online: http://www.vegetablegrafting.org/ resources/grafting-manual/ (accessed on 19 February 2020). 
32. Villasana Rojas, J.A. Tesis: Efecto del Injerto en la Producción de Tomate (Lycopersicon esculentum Mill.) Bajo Condiciones de Invernadero en Nuevo León; Universidad Autónoma de Nuevo León: San Nicolás de los Garza, Mexico, 2010; Available online: http://eprints.uanl.mx/5613/1/1080194762\%20\%281\%29.PDF (accessed on 15 April 2020).

33. Holt, J. A simple way of grafting herbaceous plants. Gdnr's Chron 1958, 143, 332. Available online: https://eurekamag.com/research/013/940/013940812.php (accessed on 19 February 2020).

34. Ito, T. Present state of transplant production practices in Japanese horticultural industry. In Proceedings of the International Symposiumon Transplant Production Systems, Transplantant Production Systems, Yokohama, Japan, 21-26 July 1992; Kurata, K., Kozai, T., Eds.; Kluwer Academic Publishers: Amsterdam, The Netherlands, 1992. [CrossRef]

35. Oda, M. Use of Grafted Seedlings for Vegetable Production in Japan. Acta Hortic. 2008, 770, 15-20. Available online: https://www.actahort.org/books/770/770_1.htm (accessed on 19 February 2020). [CrossRef]

36. Itagi, T. Studies on the production system of the grafted nurseries in fruit vegetables (Part 1). J. Jpn. Soc. Hortic. Sci. 1990, 59, 294-295.

37. Kurata, K. Cultivation of grafted Vegetables 2. Development of Grafting Robots in Japan. HortScience 1994, 29, 240-244. [CrossRef]

38. Suzuki, M.; Sasaya, S.; Kobayashi, K. Present Status of Vegetable Grafting Systems. JIRCAS-Japan International Research Center for Agricultural Sciences. 1998. Available online: https://www.jircas.affrc.go. jp/english/publication/jarq/32-2/32-2-105-112.pdf (accessed on 19 February 2020).

39. Zhao, X.; Kubota, C. Vegetable Grafting International Field Trip Report-Part I: Taiwan and Japan. 2015, pp. 1-17. Available online: http://www.vegetablegrafting.org/wp/wp-content/uploads/2013/12/VegetableGrafting-International-Field-Trip-Report-2015-Taiwan-and-Japan.pdf (accessed on 19 February 2020).

40. Chen, S.; Chiu, Y.C.; Chang, Y.C. Development of a tubing grafting robotic system for fruit bearing vegetable seedlings. Am. Soc. Agric. Biol. Eng. 2010, 26, 707-714. Available online: http://bmte.niu.edu.tw/files/ writing_journal/5/83_cc69a06e.pdf (accessed on 19 February 2020).

41. Leonardi, C.; Romano, D. Recent issues on vegetable grafting. Acta Hortic. 2004, 631, 163-174. Available online: http://www.actahort.org/books/631/631_21.htm (accessed on 19 February 2020). [CrossRef]

42. Bumgarner, N.R.; Kleinhenz, M.D. Grafting Guide: A Pictorial Guide to the Cleft and Splice Graft Methods as Applied to Tomato and Pepper. Ohio State University. Research and Development Center. 2014. Available online: http://web.extension.illinois.edu/smallfarm/downloads/50570.pdf (accessed on 19 February 2020).

43. Boutelou y Agraz, C. Tratado del injerto. Servicio de Publicaciones y Divulgación. Junta de Andalucía. Consejería de Agricultura y Pesca. Reedition 2007. 1817. Available online: http://www.biodiversitylibrary. org/item/145799 (accessed on 19 February 2020).

44. Kim, S.H.; Pham, T.D.; Kim, I.S. Effect of Grafting Position, Water Content in Substrate on the Survival Rate and Quality of Grafted Tomato Seedlings. J. Agric. Life Environ. Sci. 2016, 27, 13.

45. Pardo-Alonso, J.-L.; Carreño-Ortega, Á.; Martínez-Gaitán, C.-C.; Callejón-Ferre, Á.-J. Combined Influence of Cutting Angle and Diameter Differences between Seedlings on the Grafting Success of Tomato Using the Splicing Technique. Agronomy 2018, 9, 5. [CrossRef]

46. Yamada, H. Research for Development of the Grafting Robot for Solanaceae. J. Jpn. Soc. Agric. Mach. 2003, 65, 142-149. Available online: https://www.jstage.jst.go.jp/article/jsam1937/65/5/65_5_142/_pdf/-char/ja (accessed on 19 February 2020).

47. Pardo-Alonso, J.L.; Carreño-Ortega, Á.; Martínez-Gaitán, C.C.; Golasi, I.; Galán, M.G. Conventional industrial robotics applied to the process of tomato grafting using the splicing technique. Agronomy 2019, 9, 880. [CrossRef]

48. Johnson, S.J.; Miles, C.A. Effect of healing chamber design on the survival of grafted eggplant, tomato, and watermelon. HortTechnology 2011, 21, 752-758. [CrossRef]

49. Torres, A.P.; López, G.R. Medición de Luz Diaria Integrada en Invernaderos. Produccion Comercial de Cultivos Bajo Invernadero Y Viveros, (HO-238-SW). 2002, pp. 1-7. Available online: https://www.extension. purdue.edu/extmedia/HO/HO-238-SW.pdf (accessed on 19 February 2020).

50. Chiu, Y.C.; Chen, S.; Wu, G.J.; Lin, Y.H. Three-Dimensional Computer-Aided Human Factors Engineering Analysis of a Grafting Robot. J. Agric. Saf. Health 2012, 18, 181-194. [CrossRef] [PubMed] 
51. Lin, H.-S.; Chang, C.-Y.; Chien, C.-S.; Chen, S.-F.; Chen, W.-L.; Chu, Y.-C.; Chang, S.-C. Current Situation of Grafted Vegetable Seedling Industry and Its Mechanization Development in Taiwan. 2016, pp. 65-76. Available online: http://www.fftc.agnet.org/activities.php?func=view\&id=20160113155600 (accessed on 1 April 2020).

52. Masterson, S.A. Propagation and Utilization of Grafted Tomatoes in the Great Plains. Ph.D. Thesis, University of Alabama, Tuscaloosa, AL, USA, 2010. Available online: https://core.ac.uk/download/pdf/ 18529369.pdf (accessed on 15 April 2020).

53. Bausher, M.G.; Road, S.R.; Pierce, F. Graft Angle and Its Relationship to Tomato Plant Survival. HortScience 2013, 48, 34-36. [CrossRef]

(C) 2020 by the authors. Licensee MDPI, Basel, Switzerland. This article is an open access article distributed under the terms and conditions of the Creative Commons Attribution (CC BY) license (http://creativecommons.org/licenses/by/4.0/). 